\title{
Educator Perspectives on the Instructional Effects of One-to- one Computing Implementation
}

\author{
Andrew C. Lawrence, Adel T. Al-Bataineh, Douglas Hatch \\ Illinois State University, United States
}

Received: 18.11.2017

Accepted: 16.03 .2018

Published: 13.04 .2018

\begin{abstract}
The purpose of this study was to examine educator's perceptions regarding the quality of student learning during the implementation of a one-to-one computing program in a private secondary school in central Illinois. The sample of the study consisted of 26 teachers, administrators, and counselors who worked with 320 students during one-to-one technology implementation program. First a Likert type scale was administered and then interviews were conducted with the participants to find out their observations, perceptions, and opinions with regard to student learning. The results show that most educators believe that student learning has slightly improved with the implementation of one-to-one technology program.
\end{abstract}

Keywords: One to one technology; Technology implementation; Challenges of technology; Teacher perceptions of technology use

\section{Introduction}

In education, one-to-one computing or technology refers to the movement towards a classroom environment where each student in the classroom or school has a laptop, tablet or device to use individually in the classroom as a tool. This form of educational technology use is becoming increasingly popular in education today. Significant research is available to describe changes to teaching and learning during one-to-one technology implementation. However, as more learning environments consist of students with individual computer access, data is needed to assess and describe the impact of these one-to-one technology programs. The question that school administrations across the nation are dealing with is the extent to which these technology investments are worth the investment.

Over the past two decades, a large portion of leaders and policy makers in education have come to believe that increased access to technology in the classroom would lead to improved teaching and learning, efficiency, and other essential modern skills. In the nearer past, one-to-one computing initiatives have taken this belief into practice for an even wider range of student access. In a classroom where technology use is for all and equipment need not be shared, stakeholders seem to expect an even more expansive range of positive outcomes (Bebel \& O’Dwyer, 2010).

Of all the stakeholders involved in education, no other experiences the daily details of technology integration like teachers. In many cases, educator opinions and attitudes have helped to form, implement, and maintain school policy regarding technology implementation 
programs. Educator involvement and input is so vital that Mumtaz (2000) identified teacher beliefs as the most important indicator of success for technology implementation. Consequently, teacher perceptions of the impact of one-to-one program implementation ought to prove to be rich in detail and significant in relating program implementation to any impact on student learning.

It is well documented that technology implementation, and particularly one-to-one programs, make changes to the learning environment. The reasonable next question is whether these changes are significantly influencing the quality of student learning. In a 2012 study by Light, D. \& Pierson E, noted how the new technology "had become a daily part of learning in the classroom through a mix of pre-existing teaching and learning strategies being enriched and modified (p.6)." As technology is implemented into the classroom, certain teaching and learning strategies change and adjust.

Some research shows that particular learning environments have not yet benefitted from specific technology implementation programs. Blackley and Walker (2015) highlighted changes in middle school mathematics teaching after a course of a seven-year one-to-one laptop technology implementation. This study sought to show that the educational community's investment in technology had been worthwhile. The data, however, revealed that "little authentic integration of technology had taken place in the pedagogical practices of mathematics teachers (p. 99)."

Unfortunately, the existing research is incomplete concerning the impact of technology implementation on student learning. Some studies conclude that technology implementation improves student learning while in other studies the data shows that technology implementation has not significantly improved student learning.

Consequently, this study examined the implementation of a one-to-one computing bring-yourown-device (BYOD) program at a private, Catholic, suburban secondary school in central Illinois. In education, Bring-Your-Own-Device (BYOD) refers to a specific style of one-to-one technology implementation in which the students are the sole owners of their devices and are responsible for providing and maintaining their device such as a laptop or tablet as one of their studentsupplied school supplies. Over the course of the past five years, this secondary school has planned, prepared and implemented a learning environment where each student has individual access to his or her own computer with wireless internet access as well as cloud-based student accounts and work space. Many teachers in this school today remain in similar teaching situations as they taught before the technology program was implemented. The perspectives of these educators provide data for the changes to student learning across this secondary school as it adopted and implemented its relatively new one-to-one computing program.

In specific, the purpose of this study was to identify what educators perceive has changed regarding the quality of student learning during the implemented of a one-to-one computing program in a private, Catholic suburban secondary school in central Illinois.

\section{Literature Review}

The purpose of one-to-one classroom is to "transform students into explorers and teachers into guides. (Armstrong, 2014, p. 39)" Learning will become more than just memorizing what a teacher preaches but it will require students to attain a deeper thought process where students 
are responsible for their comprehension (Banchero, 2013). The successfulness of the one-to-one learning community is not limited to the device in use, but it is how well the teacher is able to incorporate the technology into the classroom and provide outlets for student exploration. The most significant impact a one-to-one classroom has on a student is that it creates a learner centered form of education by differentiating instruction. Students take their knowledge into their own hands and teach themselves to learn, a vital job skill. In this setting, students can decide when they have a strong understanding of the content and are ready to demonstrate their knowledge (Paulson, 2014). The literature points out that the quality of technology and students' perception of technology can impact the one-to-one learning environment.

A common thread among the current literature includes the quality of technology that is used. Studies reviewed in the study agree that the quality of pedagogical tasks and the question of how technology is being implemented in the classroom environment are critical questions when determining the effectiveness of technology with regards to improving student learning. In a study conducted by Wenglinsky (1998), results showed that technology use could improve student learning, but that this depended upon how the technology was used. Wenglinsky's study found that using technology for higher-order thinking skills and application problems was helpful to student learning while lower-order skills were negatively related to achievement. Wenglinsky also found that the frequency of school computer use was not a positive indicator. In fact, frequency of computer use had a negative impact on academic achievement. Considering the many research studies that seem to assume that increasing the frequency of technology use in schools will increase learning, this study shows otherwise. Educators should use technology with the aim of improving student learning, especially by applying higher-order thinking skills.

Conversely, Lei and Zhao (2007), conducted a study to determine a difference between good and poor technology implementation. This study proposed that the purpose for using technology determines the degree to which students will or will not benefit from using computers. Like Wenglinsky's findings, this study identifies quantity of technology use as insufficient to bringing about the student learning benefits for which educational stakeholders hope. Additionally, Lei \& Zhao found that best uses of technology may not be the most popular among the students, and they may be the most frequently used. Further study is needed to continue to clearly identify the properties of good technology so that teachers may make informed educational choices that will improve their students' learning.

A more relevant study conducted by Weston and Bain (2010), describes how the actual effects of implementing a one-to-one computing program fall significantly short of the frequently promised anticipated changes that would accompany technology implementation. This study suggests that innovation is needed with the use of technology in learning. If technology is implemented in a way that improves student interactions with learning objectives over traditional methods, then the technology tools would produce transformation in student learning.

In a more recent study, researchers found that when the technology is being used frequently and well, student achievement improves Cheema and Zhang (2013). Interestingly, the study by Cheema and Zhang found that non-educational technology use had no significant impact on student achievement. Researchers anticipate some degree of educator frustration with off-task students, and data collected regarding teacher perceptions must be analyzed with consideration of the educational spillover from even non-educational technology use. 
More importantly, the use of one-to-one technology has a wide range of benefits for bother the student and the teacher. In a study conducted in by Zucker and Hug (2007), which focused on examining the specific changes to teacher instructional practices, found that many teachers report improvement in the depth of student understanding. This study also concluded that a significant percent of teachers has changed aspects of their teaching. Some teachers reported that these teaching changes improved their organization of classroom activities. Others reported that they are better able to meet the unique needs of their students. Most teachers reported that the one-to-one computer technology is now essential to their teaching practice.

An example of implementing technology in a transformative way is found in a 2010 study from Drayton et al. The results draw out examples of authentic scientific inquiry and data analysis where students are interacting with scientific data in real time. The learning activities provided by this technology implementation shows promise beyond the lower quality learning activities identified throughout the literature. Learning activities such as those involving the science probeware, data analysis, and other such activities show much promise for the future of technology implementation (Drayton et al. (2010), p.35). Technology implementation should encourage and support the development and improvement of student learning activities beyond traditional methods.

As the implementation of technology impacts students' learning, it is necessary to examine students' perceptions of technology use in the classroom. As students are becoming more equipped with new technologies such as cellphones, laptops, and tablets, it is no surprise that students mostly have a favorable perceptions of technology use in educational settings.

In a study conducted by Beatty, et al. (2008) which trained teachers in using classroom response systems that are more commonly referred to as clickers to engage students in formative assessments, results showed that students liked using these clickers to complete formative assessments (p. 14) and one research participant noted improved timely attendance in response to the use of technology for assessment.

In another study, Nicoll and Laudato (1999) investigated many aspects of using online materials in a university course. Their study included student preferences and opinions about the usefulness of several aspects of available online materials. Of particular interest, $73.9 \%$ of students in this study agreed that they could receive feedback on quizzes and exams quickly ( $p$. 14). This is commonly noted advantage to computer-based assessments.

In a similar study, Williams and Wong (2009) compared the value of closed-book paper-based final examinations with open-resource web-based final examinations. This study of assessment format concluded that students preferred the computer-based assessment compared to the closed-book exam. The study found that the scope of cheating was about the same for both examination formats while the depth of learning was significantly improved in the computerbased assessment.

Students' perception of technology used was reported to improve students learning in a recent research study by Sivakumaran et al. (2012) which studied student perceptions of multimedia technology use in schools. Sivakumaran et al. found that students perceived that using technology more often would result in improved learning and motivation (p.67). Student perception data also showed that about half of the surveyed students used computers in their mathematics courses. 
Furthermore, students' positive perception technology is evident in online courses offered in higher education. According to a study conducted by Alston and English (2007) in which they studied the effectiveness of Web-enhanced agricultural education pedagogy, the study concluded that students perceived the online components to be useful.

Although significant research is available surrounding the implementation of one-to-one computing environments, few published research studies focus specifically on the necessities of teaching and learning in these new computing environments. Implementing a one-to-one learning environment is a complex process with many variables, expectations, and necessary support that will inevitably differ greatly from location to location. The purpose of this research was to identify what educators perceived had changed regarding the quality of student learning during the implemented of the one-to-one computing program in this private high school in central Illinois.

\section{Methodology}

This study consisted both of quantitative and qualitative research. A Likert scale survey was used to collect data regarding teacher and administrator observations and opinions on student learning before, during, and after the one-to-one technology implementation program. Interviews were conducted with a group of participants who filled out the survey and who were willing to discuss and reflect on the changes to student learning that they observed throughout the implementation of the one-to-one technology.

\section{Participants and Instruments}

The number of participants in this study were 26 educators, counselors, and administrators who worked at a private Catholic high school in central Illinois. The surveyed participants included 18 women and 8 men. The students' enrollment was 320 students.

The teaching experience of the surveyed participants varied from 4 teachers with less than three years of teaching experience, 11 teachers with four through ten years of teaching experience, 5 teachers with eleven through twenty years of teaching experience, and 6 teachers with more than twenty years of teaching experience.

The participants' level of education included 3 who have attained a bachelor degree, 14 who have earned a bachelor degree and some graduate level coursework, 5 who received a master's degree, 3 have completed graduate level coursework beyond a master's degree, and 2 who have a doctoral degree.

Lastly, participants taught a variety of subjects at this school throughout the process of implementing this one-to-one technology program. 2 participants selected social studies, 3 selected fine arts, 3 selected foreign language, 2 selected math, 3 selected science, 4 selected English, 7 selected theology, 1 selected computers, 1 selected administration, and 2 selected counseling.

Quantitative data was collected using a Likert scale survey that was administered online using Google forms. The survey included 5 demographic questions that aimed at identifying participants' gender, total teaching experience, teaching experience at this school, highest level 
of education attained, and subject area(s) taught during the process of implementing one-toone technology program.

In addition, the survey included two major sections. In the first section, participants described the frequency of their use of the one-to-one devices as well as the way in which the devices were used, the reasons for using devices, and the frequency. At the end of this section, participants were also asked to rate the degree to which they perceive student learning has improved.

The second section of this survey asked participants to comment on any changes to student learning they had observed over the course of the technology implementation process. This section of the survey targeted the classroom learning experience that may have changed due to technology implementation. Survey items asked participants to compare the following characteristics of student learning experiences: frequency of higher-level thinking task participation, organization skills, note-taking skills, preparedness for class, student contribution to class discussion, student asking for help from peers and teachers, student distraction in class, collaborative work, personalized learning experiences, quality student questions, technology fluency, study skills, and assessment performance.

The qualitative data was collected through structured interviews. The focus of the questions was related to the educator's perception of student learning and technology implementation. The interview questions were designed to foster an in-depth discussion about the educator's perception on how the technology implementation process had, or had not, impacted student learning. Interviews were audio recorded so that significant parts could be revisited and transcribed. More specifically the interviews included conversation regarding student learning with and without one-to-one technology program that participant teaches have observed. The interview questions included specific discussion of the quantity and frequency of technology use in the classroom before, during, and after implementing the one-to-one program. The interview questions also specifically included discussion of the quality of student work. Lastly, the interview questions focused on the teachers' experiences with using, or not using, the technology in their classrooms.

Several factors influenced the selection of participants who were individually interviewed. In all, three educators were chosen for several reasons. The interviewed educators all were classroom teachers before, during, and after the technology implementation process. Each specific educator was chosen to represent a broad spectrum of the teacher population at this participating school. Interviewed educators varied in teaching experience from 4 years to 30 years. Interview participants were varied in department from social studies, foreign language, and math.

\section{Research Purpose and Questions}

The purpose of this research was to identify what educators perceived had changed regarding the quality of student learning during the implemented of the one-to-one computing program in this private high school in central Illinois. 
This study collected data to answer the following research questions:

1. What are the educators' perceived changes in student learning during the implementation of a one-to-one technology program?

2. What possible teaching and learning changes took place during the implementation of a one-to-one technology program?

3. What are the experiences of educators who implement a one-to-one technology program?

\section{Significance of the Study}

The results of this study are usefully in relation to educator perceptions of student learning during the process of implementing a one-to-one computing program. Specifically, this study can serve as a model for other schools that intend to implement a one-to-one technology program. More importantly, data from this study can be used as an accountability measure for this secondary school's stakeholders. This school, and the families who attend it, have made investments in technology to implement this program. Data from this study should show the effects the one-to-one program has had on student learning from teachers' point of view.

\section{Limitations of the Study}

The primary limitation with this research is its small sample size and scope. This research was conducted only within one private secondary school. Because this survey is intended to this private high school in central Illinois, the findings will be most relevant to this school and schools in similar environments and enrollments, or schools in this school's district that may also find the findings useful.

It has been the hope of the researchers that the findings and implications of this research will contribute to the ongoing professional discussion about what teaching practices are best for implementing technology in a variety of educational settings. This focused research study has provided several specific examples of technology implementation that does affect student learning in specific and concrete ways. Because of the private nature of the participating school, data is limited in this schools setting.

\section{Results}

The purpose of this study was to identify what educators perceive has changed regarding the quality of student learning during the implementation of a one-to-one computing bring-yourown-device program.

Data was collected using mixed methods. Educators completed a Likert style survey regarding student learning, and individual interviews were conducted with a small group of educators. The quantitative survey received 26 responses out of a possible 29 responses for a $90 \%$ rate of return. Participant demographic information is shown in table 1 below. Qualitative interviews were conducted with 3 participating educators. 
Table 1. Participants' Demographic Information

\begin{tabular}{|c|c|c|}
\hline Survey question & $f$ & $\%$ \\
\hline \multicolumn{3}{|l|}{ Gender } \\
\hline Male & 8 & 30.8 \\
\hline Female & 18 & 69.2 \\
\hline \multicolumn{3}{|l|}{ Level of Education } \\
\hline Bachelor's Degree & 3 & 11.5 \\
\hline Some post-Bachelor's & 14 & 53.8 \\
\hline Master's Degree & 5 & 19.2 \\
\hline Some post-Master's & 4 & 15.4 \\
\hline Doctorate or beyond & 0 & 0 \\
\hline \multicolumn{3}{|l|}{ years of teaching experience } \\
\hline $0-3$ years & 4 & 15.4 \\
\hline $4-10$ years & 11 & 42.3 \\
\hline $11-20$ years & 5 & 19.2 \\
\hline more than 30 years & 3 & 11.5 \\
\hline \multicolumn{3}{|l|}{ Teaching or Administrative duties include } \\
\hline Social Studies & 2 & 6.9 \\
\hline Fine Arts & 3 & 10.3 \\
\hline Foreign Language & 3 & 10.3 \\
\hline Math & 2 & 6.9 \\
\hline Science & 3 & 10.3 \\
\hline English/Language Arts & 4 & 13.8 \\
\hline Theology & 7 & 24.1 \\
\hline Wellness/Health/Physical Education & 0 & 0 \\
\hline Technology/Business/Computers & 1 & 3.4 \\
\hline Administration & 1 & 3.4 \\
\hline Counseling & 1 & 3.4 \\
\hline Other & 2 & 6.9 \\
\hline \multicolumn{3}{|l|}{ Teaching at this school prior to $1: 1$} \\
\hline Yes & 17 & 65.4 \\
\hline No & 9 & 34.6 \\
\hline
\end{tabular}

Demographic data shows that most of responses come from female educators. Most responding educators had less than 11 years of total teaching experience and less than 11 years of teaching experience at this school. Most responding educators have completed some post-Bachelor's Degree education. A variety of teaching or administrative duties were represented by the responses with the fewest responses coming from teachers of health and wellness and most responses coming from teachers of theology. Lastly, the demographic data shows that most responding educators were teaching at this school before the implementation of the one-to-one technology program. 
Table 2. Educator Experiences with Implementing One-to-one Technology

\begin{tabular}{lll}
\hline Survey question & $f$ & $\%$ \\
\hline Do you think student learning has improved with the 1:1 program? & & \\
Learning has diminished significantly & 2 & 8.3 \\
Learning has diminished some & 1 & 4.2 \\
Learning has diminished slightly & 1 & 4.2 \\
Learning has improved slightly & 6 & 25 \\
Learning has improved some & 11 & 45.8 \\
Learning has improved significantly & 2 & 4.3 \\
Learning has remained unchanged & 1 & \\
& & \\
How frequently are deceives used? & & 52 \\
Every day & 13 & 28 \\
2-3 times a week & 7 & 4 \\
Once a week & 1 & 16 \\
A few times a month & 4 & 0 \\
Never & 0 & \\
\hline
\end{tabular}

Data shown in table 2 is perhaps the most relevant data from this research survey. The first question shows that most responding educators believe student learning has improved with the implementation of the one-to-one technology program. The second question shows that most of the responding educators use devices each day, and eighty percent of responding teachers use devices at least a few times a week. 
Table 3. The Uses of One-to-one Technology

\begin{tabular}{lll}
\hline Survey Question & $f$ & $\%$
\end{tabular}

How often are devices used for formative assessment?

Rarely: 1

$\begin{array}{ll}9 & 36 \\ 5 & 20 \\ 6 & 24 \\ 5 & 20\end{array}$

Often: 4

How often are devices used for summative assessment?

Rarely: 1

2

4

3

1

4.2

Often: 4

How often are devices used for notetaking?

Rarely: 1

Often: 4

How often are devices used for group work or collaboration?

Rarely: 1

8

32

2

3

12

Often: 4

8

32

$6 \quad 24$

How often are devices used for Internet research?

Rarely: 1

$9 \quad 36$

2

$3 \quad 12$

3

10

10

Often: 4

3

3

How often are devices used for accessing course materials electronically?

Rarely: 1

\section{4} 16

4

3

3

12

Often: 4

Table 3 shows in more detail how the responding educators use computer devices. This data is relevant for answering the research question: what possible teaching and learning changes took place during the implementation of a one-to-one technology program? The data shows that few educators use devices for summative assessments with $75.0 \%$ of the responding educators choosing rarely. Data also shows that most responding educators, $56.0 \%$, often use devices to access course materials electronically. 
Table 4. Educator Observations of the Change in Students Learning

\begin{tabular}{|c|c|c|}
\hline Survey question & $f$ & $\%$ \\
\hline \multicolumn{3}{|c|}{ After the technology implementation students: } \\
\hline \multicolumn{3}{|c|}{ Demonstrate better organization skills than before } \\
\hline Strongly disagree & 1 & 5.9 \\
\hline Disagree & 3 & 17.6 \\
\hline Agree & 8 & 47.1 \\
\hline Strongly agree & 3 & 17.6 \\
\hline Neither agree or disagree & 2 & 11.8 \\
\hline \multicolumn{3}{|c|}{ are more likely to ask for help from their teacher than before } \\
\hline Strongly disagree & 1 & 5.9 \\
\hline Disagree & 3 & 17.6 \\
\hline Agree & 4 & 23.5 \\
\hline Strongly agree & 1 & 5.9 \\
\hline Neither agree or disagree & 8 & 47.1 \\
\hline \multicolumn{3}{|c|}{ are more likely to ask for help from a peer than before } \\
\hline Strongly disagree & 1 & 5.9 \\
\hline Disagree & 1 & 5.9 \\
\hline Agree & 9 & 52.9 \\
\hline Strongly agree & 1 & 5.9 \\
\hline Neither agree or disagree & 5 & 29.4 \\
\hline \multicolumn{3}{|c|}{ experience fewer distractions in class than before } \\
\hline Strongly disagree & 11 & 64.7 \\
\hline Disagree & 3 & 17.6 \\
\hline Agree & 1 & 5.9 \\
\hline Strongly agree & 1 & 5.9 \\
\hline Neither agree or disagree & 1 & 5.9 \\
\hline \multicolumn{3}{|c|}{ use technology more fluently than before } \\
\hline Strongly disagree & 0 & 0 \\
\hline Disagree & 0 & 0 \\
\hline Agree & 9 & 52.9 \\
\hline Strongly agree & 4 & 23.5 \\
\hline Neither agree or disagree & 4 & 23.5 \\
\hline
\end{tabular}

Data from able 4 is relevant for answering the research question regarding: what are the educators' perceived changes in student learning during the implementation of a one-to-one technology program? Perhaps the single most consistent response in this survey is that nearly all responding educators disagree or strongly disagree that students experience fewer distractions in class than before the technology implementation. Most responding educators also indicated that students are more likely to ask for help from a peer than before. Most of responses indicated that students are more organized than before, and nearly half of the responding educators indicated that there has been no change in how likely students are to ask 
for help from their teacher. Nearly all responding educators indicated that students use technology more fluently than before.

In addition to completing the Likert scale, a small group of participants were invited to participate in interviews. The interviews were conducted to provide another means to validate any findings that may come from the quantitative survey results. Interviews were conducted with three different teachers of varied experience, field, expertise, and comfort level with the one-to-one technology implementation.

The three interview participants have been given the pseudonyms Ms. Clark, Mrs. Brown, and Mr. Anderson. All three are currently teachers at the same private, Catholic, suburban high school in central Illinois. Each had been teaching at this school before and after the implementation of the one-to-one program. Ms. Clark teaches foreign language, Mrs. Brown teaches mathematics, and Mr. Anderson teaches social studies and fine arts. Ms. Clark has 4-10 years of teaching experience total and at this school, Mrs. Brown has 21-30 years of teaching experience total and at this school, and Mr. Anderson has 11-20 years of teaching experience total and at this school. Mr. Anderson's highest level of education includes some post-Master's degree courses. Ms. Clark and Mrs. Brown have both completed some post-Bachelor's degree education.

The first major interview question discussed the changes that have come to the classroom with the implementation of the devices. Each teacher reflected on how frequently students use computer devices and on the types of learning activities that students participate in with the devices. Mr. Anderson and Ms. Clark indicated that their students use devices every day. Mrs. Brown's students rarely use devices. Students in Mr. Anderson's class uses devices for note taking, for accessing course materials, and for Internet research. Students in Ms. Clark's class use devices to access course materials. Students in Mrs. Brown's class do not really use devices except perhaps a smartphone calculator app if a student forgot a traditional calculator. Ms. Clark's Spanish textbook has an online suite that students access in class many times. Her students also use Quizlet flashcards to review vocabulary. Ms. Clark adds that these same materials could easily be accessed without a computer. Mr. Anderson appreciates the immediate Internet research that is available in the middle of his classroom's discussions. He also adds that many students find confidence to back up their opinions with information they can research from the Internet at a moment's notice.

The second interview question asked the participating teachers to compare the student learning before the implementation of the one-to-one devices to after. This question specifically asked participants to discuss any ways learning has improved and any ways that learning has been harmed by the introduction of devices.

Mrs. Brown does not think that the implementation process has improved student learning at all. She expressed how student attention span, work ethic, and perseverance on a math problem seems to have decreased with the increase of technology. Mrs. Brown has concerns about students missing out on a sense of wonder and awe about their learning because of distractions and of a diminishing work ethic.

Ms. Clark thinks that it is hard to tell if the implementation process has improved student learning or not because there are too many variables to consider. Many of the aspects of learning unclear whether they are related to the computer use for Ms. Clark's classroom. She discussed concerns about student distractions, a lack of student motivation, and a loss of a 
student's feel for reality. It seemed like the devices were sometimes a good tool for Ms. Clark, but that at other times they were too much of a distraction. She noted how it is not always possible to monitor students who may be off task in the middle of teaching.

Mr. Anderson discusses several significant improvements in student learning in his class. One of these positives is how students are constantly able to fact-check any information presented in class. Mr. Anderson fosters a discussion based classroom where he says that "the more possible correct answers, the better." He cites an ability for all his students to look up evidence to support their opinions as a significant boost to student confidence. He says, "the quality of questions has been phenomenal," and the students are constantly evaluating and comparing their sources with others. This allows a higher level of thinking to flourish and empowers students to take a stand with their opinions even if others disagree. Ultimately, Mr. Anderson does not see any negatives. He says, "his authority has been challenged more, and this is a good positive because it is putting agency in student knowledge." When asked about a downside to devices in the classroom, Mr. Anderson points out that there have always been students who have a hard time paying attention. He does not think that more students are distracted in class today than before the devices. Rather, he thinks that the distracted students are more distracted than they used to be. Mr. Anderson also talked some about the challenges of Internet based collaboration and cheating as well as the professional development required to convert good device-free lessons into good device friendly lessons. These topics will be incorporated in further parts of this research.

Lastly, the researchers asked each participating teacher if there were any other topics we should be discussing in our interviews. Ms. Clark talked about how she feels like she needs more training on how to use the technology in a creative way. "Even with the professional development that we did receive, I feel unsure about what I should be doing with the technology," she said. Mrs. Brown said, "there have always been students who didn't want to work...it feels different now... like the bell curve has moved a little bit [towards the lazier side]." Mr. Anderson said, "technology does not educate, educators educate," and he went on to describe how technology is a tool, and if it is used properly it should only help student learning. The key is determining in each individual classroom how to meet the needs of the students. Each of these topics, professional development, student work ethic, and technology as a tool, will be discussed in greater detail later in this research.

In conclusion, the results of this study showed demographic variation for responding educators along with their varied experiences in implementing the technology and in their perceptions of changes in student learning. Responding educators represented the entire demographic range of educators at this secondary school. Most responding educators reported using the technology in their courses each day but for different purposes and learning activities. The average of all the responding educators found that student learning has improved slightly to improve some with the implementation of the one-to-one technology program.

\section{Discussion}

The purpose of this study was to identify what educators perceive has changed regarding the quality of student learning during the implementation of a one-to-one computing bring-yourown-device program. 
Previous research on the effects on implementing one-to-one technology in the classroom at first focused mostly on frequency of technology use in the classroom. Later research has shown that quality of technology use is a much better indicator of improvement in student learning. For example, a study conducted by Wenglinsky (1998), showed that technology use could improve student learning, but that this depended upon how the technology was used. Wenglinsky's results showed that using technology for higher-order thinking skills and application problems was helpful to student learning while lower-order skills were negatively related to achievement. This study found that the frequency of school computer use was not a positive indicator. In fact, frequency of computer use had a negative impact on academic achievement. Data from this research offers further support for Wenglinsky's findings that frequency of technology use is less effective than the quality of technology use.

Interviews data also supports the claim of prior research that the quality of device use matters much more than the frequency of use. Mr. Anderson and Ms. Clark both indicated that their students use devices in class every day; however, the two held different opinions on changes in student learning. Mr. Anderson is overwhelmingly positive about the improved quality of student learning. He cites quality student discussion, improved Internet research skills, and confidence of his students with the use of devices. On the other hand, Ms. Clark indicates that the way in which she most often uses devices could be replaced by the textbook and that she is searching for more creative ways to use the devices. Both Clark and Anderson say that devices have improved student learning, but consistent with prior research, Anderson is more positive about the improved learning and uses the devices for higher level thinking tasks. This example mirrors discussion from a 2010 article by Weston \& Bain where Clark's methods are described as replacement methods because the traditional textbook instruction is continued with the textbook simply being replaced by an Internet book source. Weston \& Bain continue to say simply "replacement methods do not improve student learning." Clark and Anderson's extensive use of technology but to significantly different effects illustrates this trend in the current research. Innovative pedagogical techniques are needed because simply replacing the textbook approach with an online textbook does not improve learning.

Furthermore, interviews provide some insight into the student perception. All three qualitative interview subjects discussed the ways in which students use the devices and how student interactions in class have changed. Mrs. Brown and Ms. Clark each individually discussed how students seem to interact differently with them in class. They contribute some of this less positive interaction to the devices and to the culture of using the one-to-one devices frequently in school. When the students have a few minutes before or after a lesson or between activities, Ms. Clark says the students "are back on their computer games or studying for another class on their computer." Both Brown and Clark discussed how the healthy thinking that happens outside of the scheduled times in class seems to be missing in their students. A lack of daydreaming that Brown and Clark identified seems to reduce sense-making questions like "Mrs. Brown, if the earth is a sphere, why is the horizon flat?" that would commonly add realism to an academic topic. From another point of view, Mr. Anderson is thrilled at the increase in the confidence of students in his classroom as they enter discussion with their one-to-one devices. It seemed like before this implementation that students were mostly unwilling to hold an opinion on their own and back it up outside of the majority opinion, but with the devices, students are comfortable to look up research and support their claim with the use of the devices. This is a significant plus for Anderson's class and for student confidence throughout their learning. Overall, it appears student interactions are changing to mixed results from the educators' point of view. 
In addition, all interviewees discussed student distraction in conjunction with student perception. In the current research, the effects of student distraction have been fixed. Cheema and Zhang (2013) studied the effect of quantity and quality of technology use on student achievement and found that non-educational technology use had no significant impact on student achievement. Their study anticipated some degree of educator frustration with off-task students, and data collected regarding teacher perceptions must be analyzed with consideration of the educational spillover from even non-educational technology use. Consistent with Cheema and Zhang's research, however, Mr. Anderson discussed how there have always been distracted students in class. The problem now, he states, is that "the distracted students can be more distracted." However, research into these fringe distractions by Cheema and Zhang does not show that these distractions reduce student achievement. In fact, Anderson and Clark discussed in their interviews how many times their distracted students are distracted by good things such as Internet news and studying current events or vocabulary review from other academic subject areas. One may even argue that more responsibility is being placed on individual students' time management skills.

Overall, this study neither refutes nor supports research on student perceptions. This study can say that educators do perceive frequently using computer devices help improve student motivation. This study also presents mixed results into student distraction. Some of this study results seem consistent with studies like Cheema and Zhang (2013) in suggesting that the distracted student does not harm student achievement. Other interview data would refute this. "I see more disadvantages than advantages from where I sit," said Mrs. Brown about her perception of distracted students' diminished student learning.

Much of the current research regarding one-to-one technology implementation discusses challenges to the implementation of one-to-one technology. Many research studies cited a need for further research into teacher needs such as professional development and training to ensure that the implemented technology will be well used. Although this was not the focus of this present research, the qualitative interviews could not keep from reflecting some on teacher professional development needs.

Two of the three interviewees discussed teacher professional development and training to implement the one-to-one technology program. The interview with Ms. Clark made it clear that she would like to have more professional development and get specific training on how to use the one-to-one devices more efficiently as an instructor. It seems like it is easy to use the technology the same way the teachers used to use their textbook, but this is not the point of having the devices. Ms. Clark would like training on creating interactive lessons and higher quality learning activities. This seems consistent with trends from prior research such as a 2015 study by Warschauer \& Tate that identified how the technology is used in the classroom as the single most important aspect to consider in implementing one-to-one computing. Warschauer \& Tate echoed other research by stating that using technology to do the same learning tasks in a new format is insufficient change and will not transform student learning.

Ms. Clark's experiences and prior research seem to suggest that teachers who receive more professional development tend to have more successful one-to-one technology programs. Mr. Anderson discussed a process of professional development to gradually improve teaching practice and methods for incorporating technology. The biggest negative according to Mr. Anderson, is "not maximizing the potential of using these devices," and that he could not make the transition all at once. Although the curriculum he taught stayed the same, many aspects of teaching pedagogy must change to make the best use of the devices. Anderson discussed how 
many lessons were not as good as they are now because he had not had the time to completely implement his new teaching with devices pedagogy. In this respect, it sounds like Mr. Anderson has achieved the level of confidence with his teaching pedagogy that Ms. Clark seeks. The process by which a teacher reaches this pedagogical level and confidence level is a worthwhile future research goal.

Overall, the present research fits nicely with previous research on implementing one-to-one technology. Quality of instruction clearly affected student learning more than frequency of using devices. Student perceptions remain a significant area of study although and is especially mixed in results regarding student distraction. Effective implementation will remain a challenge as part of educators' experiences in implementing technology. Results seems to suggest that further study is needed to determine what support teachers need to reach the level of confidence and pedagogical training that will maximize the learning potential of one-to-one devices.

Data from the interviews also corresponds with topics regarding how devices are used in the classroom or educator experiences incorporating technology. Mrs. Brown, for example says that she not really uses devices in the classroom because they are more of a distraction than a help. Brown's statement fits with the strong and moderate correlations discussed above because she does not use devices in class for formative assessments, accessing course materials, or individualized learning tasks. Mrs. Brown perceives student learning to have diminished significantly and she does not use devices for independent extra practice. Since Brown does not use devices and perceives them to harm student learning, her data is the converse of the average data because she does not use devices and perceives them to harm student learning while the trend in the data has educators that use devices frequently and perceive student learning to improve.

Furthermore, interviews show some trends regarding how educators use technology in their classrooms. Clark uses devices daily in class and mostly to access an online textbook and online course resources. She discussed that she would like to develop higher level and more creative learning activities to use with the devices and is concerned about the student distraction piece that will be discussed in more detail to come. Both reasons have Ms. Clark considering if to use the devices as much in the future. Presently, she clearly uses devices daily and uses them to access course materials electronically.

Overall, the ways in which responding educators use one-to-one technology devices with their students does seem to impact the frequency of device use and the educator perception that student learning has improved and is particularly in support of current research on the quality of technology use in the classroom. This study has shown qualitatively and quantitatively that teachers who use devices to access course materials electronically tend to use devices frequently. Present research supports the conclusion that simply using technology to replace textbook style lessons is ineffective and that complete pedagogical reform is needed for students to see significant learning improvement. More research is needed to determine precisely how this pedagogical reform ought to be best brought about. Mr. Anderson and other responding educators are using devices to different and more positive results than most of their coworkers, and future research would do well to determine what it is that they are doing differently and better for improving student learning.

The final section of the quantitative survey asked responding educators about their perception of any changes in student learning from before the implementation of the one-to-one technology program to after. Previous research informed this section by suggesting that 
educators have several methods for measuring improved student learning. Different survey questions were included based upon previous research studies and what educators commonly found improved or did not improve student learning. A 2007 student conducted by Lei \& Zhao was one such study that sought to determine a difference between good and poor technology implementation. Lei \& Zhao identified some of the best uses of technology may not be popular among the students but are likely to be the most frequently used.

Some of these observations of change were observable in the qualitative interviews as well. Both Mr. Anderson and Ms. Clark discussed students taking notes on devices. Neither of them discussed if the notes were better quality than in the past, but both stated that this was a common practice for students using devices in class. In the interview with Mr. Anderson, higher level thinking tasks were perhaps Anderson's favorite positive change with devices. This is consistent with having student complete higher-level thinking tasks more frequently. Mr. Anderson's students do more evaluating sources and analyzing conflicting points of view with the devices in class. He described it as "being constantly fact-checked" by the students who would do Internet research during the class discussion. The higher-level thinking described by Anderson in his interview is a good example of the higher-level thinking tasks that strongly correlates with positive changes in student learning.

\section{Conclusions}

The purpose of this present research was to study educator perception of student learning during the implementation of a one-to-one technology program. This research sought to better understand educator experiences while implementing technology, possible learning changes that took place, and possible changes to student learning.

Most notably, this present research supported prior research that showed teachers with higher levels of education are more likely to perceive improvement in student learning and more significant improvement in student learning than less highly educated educators. These present findings also show that the learning activities for which the technology is used affect the degree to which the educators perceive learning to improve. Simply replacing an in-print textbook with an in-the-cloud online source did not improve student learning and rather seemed to diminish learning; however, revising teaching pedagogy to incorporate technology as another learning tool did show significant improvements in student learning.

As educators are encouraged to incorporate technology into their classes and as schools move towards more modern learning environments, the implications of this present research become more significant. The ways in which technology are used do affect how well the students learn. Teacher education and training for adapting pedagogy and using digital tools should be a significant part of teacher training and professional development if one-to-one technology programs are to be most effective. School districts, administrators, and individual educators would do well to reflect on their teaching practice and professional development regarding their comfort level with adjusting the ways in which they teach. What you teach may remain, but consider changing how you teach to maximize student learning with the use of one-to-one technology devices.

Many options remain available for future study. Future studies should give as many examples as possible of teachers successfully implementing pedagogy changing one-to-one technology programs that improve student learning. Educators need to hear more samples of successful 
implementation strategies that work in the cases of individual teachers. A future study with a larger demographic range and more participants could more accurately determine which types of professional development, teacher training, and teaching practices are most effective in implementing technology well. There would also be advantages to collecting data on the practice of more specific groups of teachers such as only teachers of mathematics or only teachers of social studies. A more similar group of educators may yield more precise implications for teachers.

\section{References}

Armstrong, A. (2014), Technology in the classroom: It's not a matter of 'if,' but 'when'. Education Digest, 39-46. Retrieved on 13 September 2015 from http://sks.sirs.com.

Alston, A. J. \& English, C. W. (2007). Technology enhanced agricultural education learning environments: An assessment of student perceptions. Journal of Agricultural Education, 48(4), 1-10. doi: 10.5032/jae.2007.04001.

Banchero, S. \& Phillips, E. (2013, October 15). Schools learn tablets' limits. Wall Street Journal. Retrieved on 13 September 2015 from http://sks.sirs.com.

Beatty, I. D., Feldman, A., Lee, H., St. Cyr, K. \& Harris, R. (2008, April). Teacher learning of technology-enhanced formative assessment. Paper presented at the Annual International Conference of the US National Association for Research in Science Teaching (NARST). Baltimore, MD. ERIC: \#ED502258.

Bebel, D. \& O'Dwyer, L.M. (2010). Educational outcomes and research from 1:1 Computing settings. Journal of Technology, Learning, and Assessment, 9(1). Retrieved on 13 September 2015 from http://www.jtla.org.

Blackley, S. \& Walker, R. (2015). One-to-one laptop programs: Is transformation occurring in mathematics teaching? Issues in Educational Research, 25(2), 99-117. Retrieved on 13 September 2015 from http://www.iier.org.au/iier25/blackley.html

Cheema, J. R. \& Zhang, B. (2013). Quantity and quality of computer use and academic achievement: Evidence from a large-scale international test program. International Journal of Education and Development Using Information Communication Technology, 9(2), 106. Retrieved on 13 September 2015 from http://ijedict.dec.uwi.edu/include/ getdoc. php?id=5529\&article $=1626$

Drayton, B., Falk, J.K., Stroud, R., Hobbs, K., \& Hammerman, J. (2010). After installation: Ubiquitous computing and high school science in three experienced, high-technology schools. Journal of Technology, Learning, and Assessment, 9(3). Retrieved on 24 September 2015 from http://www.jtla.org.

Lei, J. \& Zhao, Y. (2007). "Technology use and student achievement: A longitudinal study." Computers \& Education, 49, 284-296.

Light, D. \& Pierson, E. (2012). Highlighting changes in the classrooms of a successful one-to-one program in rural Argentina: Case studies of Todos Los Chicos en la Red in San Luis. New York, NY: EDC. Center for Children and Technology.

Mumtaz, S. (2000). Factors affecting teachers' use of information and communications technology: A review of the literature. Journal of Information Technology for Teacher Education, 9(3), 319-342. doi: 10.1080/14759390000200096. 
Nicoll, J. M. \& Laudato, N. C. (1999, October). Assessing the impact on students of online materials in university courses. Paper presented at EDUCAUSE '99. Long Beach, CA.

Paulson, A. (2014, Apr 20). Blended learning revolution: Tech meets tradition in the classroom. Christian Science Monitor. Retrieved on 13 September 2015 from http://sks.sirs.com.

Sivakumaran, T., Garcia, K., Davis, L., Jones, Q., Choi, J., Dawson, M., (2012). Student perceptions of multimedia technology integrated in classroom learning. International Journal of Humanities and Social Sciences, 2(11), 67-70.

Warschauer, M. \& Tate, T. (2015). Going one-to-one, 2.0. Educational Leadership, 72(8), 60-65.

Wenglinsky, H. (1998). Does it compute: The relationship between educational technology and student achievement in mathematics. Princeton, NJ: Educational Testing Service.

Weston, M.E. \& Bain, A. (2010). The end of techno-critique: The naked truth about 1:1 Laptop initiatives and educational change. Journal of Technology, Learning, and Assessment, 9(6). Retrieved on 24 September 2015 from http://www.jtla.org.

Williams, J. B. \& Wong, A. (2009). The efficacy of final examinations: A comparative study of closed-book, invigilated exams and open-book, open-web exams. British Journal of Educational Technology. 40, 227-236. doi: 10.1111/j.1467-8535.2008.00929

Zucker, A.A. \& Hug, S.T. (2007). A study of the 1:1 Laptop Program at the Denver School of Science \& Technology. Denver, CO: Denver School of Science and Technology.

Correspondence: Adel T. Al-Bataineh, Professor, School of Teaching and Learning, College of Education, Illinois State University, Normal, Illinois, United States 